\title{
Krisis of het afscheid van de filosofie?
}

René Boomkens

Krisis 40 (1): 36-47.

\begin{abstract}
The founders of Krisis saw their journal as part of Rudi Dutschke's 'long march through the institutions': a philosophical journal that would criticize and change the practices and institutions of academic philosophy from within. Philosophy should play a critical and emancipatory role in society and in intellectual and public debates, and the journal could help to enhance that role. Academic philosophy did change, but in a rather different direction: new public management took over and submitted academic research and education to a new regime of entrepeneurial efficiency and disciplinary competition. To survive, Krisis metamorphosized several times and is now a broad bilingual online journal for intellectual debate and research with a loose relationship with academic philosophy. If it strengthens this identity, it can continue to play an intermediary role between academic research and public debate, in both directions.
\end{abstract}

\section{Keywords}

Dutch philosophy, Philosophical journals, Intellectual history, Critical theory, Empirical philosophy.

DOI

$\underline{10.21827 / \mathrm{krisis} .40 .1 .36974}$

\section{Licence}

This work is licensed under a Creative Commons Attribution-NonCommercial 3.0 License (CC BYNC 3.0). 


\section{Krisis of het afscheid van de filosofie? \\ René Boomkens}

\section{Centraal, inter of ....trans? Post?}

Toen veertig jaar geleden het filosofisch tijdschrift Krisis werd opgericht door zeven filosofiestudenten uit Amsterdam, was de 'lange mars door de instituties' die ruim een decennium eerder was afgekondigd door de Duitse 'student-revolutionair' Rudi Dutschke vermoedelijk in een beslissend stadium terechtgekomen: zou het nog wat worden met die revolutie? En waar ging die eigenlijk precies om? Dutschkes idee van een lange mars door de instituties was een poging om de rebellie van 'mei ' 68 ' - die enorme, over meerdere continenten verspreide opstand tegen 'de autoriteiten', maar ook tegen een bepaald soort autoriteit als zodanig (regentesk, masculien en patriarchaal, in dienst van 'kerk en kapitaal') - om te zetten in een serieuze poging om de bestaande instituties (staat, onderwijs en wetenschap, economie) 'van binnenuit' te revolutioneren. De oprichters van Krisis, waaronder de auteur van dit artikel, plaatsten hun tijdschrift duidelijk in het verlengde van Dutschkes oproep: het blad moest de ingeslapen en onvruchtbare academische filosofie nieuw leven inblazen, het filosofische debat en de kritische filosofie stimuleren, en de filosofie weer relevant maken voor politiek en samenleving. Oude, vermolmde instituties zouden dankzij de kritische interventies in het tijdschrift worden ondermijnd, vernieuwd, verbeterd, of scherper: gedemocratiseerd. Filosofische of ideologische inspiratiebronnen: Karl Marx en de marxisten, de Kritische Theorie en in het bijzonder Jürgen Habermas, maar ook het feminisme en de destijds nog jonge academische discipline vrouwenstudies, de 'structuralistische' marxist Louis Althusser die het tijdschrift zijn naam bezorgde (hij had het over de crisis in het marxisme), sociologische actieonderzoekers en na een jaar of twee vooral ook de Franse 'poststructuralisten', ofwel Michel Foucault en in mindere mate Gilles Deleuze of Jean-François Lyotard. Met zoveel verschillende inspiratiebronnen zou die lange mars uiteindelijk wel iets opleveren!

Het is zinvol om wat langer stil te staan bij dat beeld van een lange mars door de instituties. Ik denk dat Rudi Dutschke die metafoor ontleende aan de beroemde lange mars van Mao's Chinese communisten in 1935, zonder daarbij werkelijk op de hoogte te zijn geweest van de gruwelijke details van die onderneming. Het beeld van een lange mars moest, net als bij Mao, hoop en vertrouwen bieden: de explosie van culturele en politieke rebellie was een mooi begin, 
maar werkelijke verandering zou niet het product van een kortstondige en heftige opstand of revolutie moeten zijn, maar van een langdurig, intensief en geleidelijk proces, geen omverwerping van de bestaande instituties, maar inderdaad: een lange mars door die instituties heen. Een dergelijk beeld roept haast onvermijdelijk een andere metafoor op, namelijk die van het verschil tussen een bewegingsoorlog en een stellingenoorlog, een verschil dat de Italiaanse marxist Antonio Gramsci in de jaren dertig gebruikte om zijn hegemonieconcept nader te duiden: anders dan in het leninistische begrip van de communistische revolutie gaat het in de strijd om de politieke macht niet zozeer om een eenmalige, gewelddadige bestorming van de Bastille of het Winterpaleis (een bewegingsoorlog die het gemunt heeft op het centrum van de macht), maar om een veel geleidelijker proces (een stellingenoorlog) waarin geweld of dwang veel minder centraal staan en het winnen van de hearts and minds een cruciale factor is in het verwerven van de hegemonie.

Impliciet sloot de oprichting van Krisis als een kritisch filosofietijdschrift aan bij die gramsciaanse conceptie van politieke macht en hegemonie. Immers: enerzijds beschouwde de redactie zich nadrukkelijk als onderdeel van en geïnspireerd door de politieke idealen van de toenmalige studentenbeweging, anderzijds was de hele idee van een filosofisch (of wetenschappelijk) tijdschrift juist de erkenning van het feit dat die politieke idealen niet op stel en sprong gerealiseerd konden worden, maar juist "een zaak van lange adem" waren, zoals de titel luidt van een historische terugblik op de hoogtijdagen van de Nijmeegse socialistische uitgeverij SUN en de daarmee nauw verbonden socialistische studentendrukkerij SSP en de linkse boekhandel De Oude Mol. Auteur van de terugblik Ruud Abma was zelf in die jaren onder andere redacteur van het door de SUN uitgegeven tijdschrift Psychologie \& Maatschappij, dat nauw verwant was aan Krisis, dat zelf overigens ook jarenlang bij de SSP werd gedrukt (Abma 2019). Een zaak van lange adem: wie de samenleving wilde veranderen, diende zich voor te bereiden op een langdurige, en vooral ook intellectuele onderneming: niet alleen de politieke instituties en praktijken moesten worden aangepakt, ook wetenschap en onderwijs (de 'ideologische staatsapparaten', om de terminologie van Louis Althusser te gebruiken) dienden grondig te worden veranderd. De redactie van Krisis zag het tijdschrift als een instrument in dat veranderingsproces, dat begin jaren tachtig crescendo leek te gaan. Links, kritisch, progressief en alternatief waren de adjectieven waarmee recente veranderingen aan de universiteiten getypeerd konden worden: feminisme en vrouwenstudies, wetenschap \& samenleving, 
wetenschapswinkels, homostudies, vooral in de sociale en natuurwetenschappen kwamen allerlei alternatieve en kritische onderzoekspraktijken en lesprogramma's tot ontwikkeling. Dankzij de nieuwe, meer democratische bestuursstructuur van de Nederlandse universiteiten konden studenten meer dan ooit hun stempel drukken op wetenschappelijk onderwijs en onderzoek, en een filosofisch tijdschrift als Krisis kon daarin een belangrijke rol vervullen.

De manier waarop de academische filosofie in Nederland was georganiseerd bood bovendien alle gelegenheid om een kritische filosofiepraktijk te ontwikkelen. Filosofie werd bedreven aan zogeheten Centrale Interfaculteiten, een model dat in 1960 werd ingevoerd. 'Centraal' verwijst naar de klassieke status van de filosofie als moeder van alle wetenschappen, een status die de filosofie echter al een tijdje kwijt was. 'Inter' suggereert dat de filosofie niet boven, maar tussen de (andere) wetenschappen in staat, als een soort bemiddelaar. Zonder de morele of epistemologische superioriteit die het voorvoegsel 'centraal' aankleefde, had de kwalificatie 'inter' wel degelijk betekenis: anders dan de diverse wetenschappelijke vakdisciplines ontwikkelden filosofen kennis en ervaring op het terrein tussen de deskundigheden van de verschillende wetenschappen in, vooral ook omdat veel filosofiestudenten hun studie combineerden met een van de 'vakwetenschappen', met sociologie, rechten, biologie, et cetera. Institutioneel werd dit bovendien uitgedrukt in het gegeven dat diverse filosofiehoogleraren aan de Centrale Interfaculteit een dubbelbenoeming hadden: zij hadden tegelijk een aanstelling aan een van de andere faculteiten. Hier kwam dus in feite de filosoof als kritische theoreticus tot zijn recht, de filosoof die niet vanuit een hogere autoriteitspositie spreekt, maar vanuit een kennis van en ervaring met uiteenlopende disciplines. Ook al werd in veel gevallen een weinig concrete invulling gegeven aan die dubbelbenoemingen, het valt niet te ontkennen dat de Centrale Interfaculteiten, ondanks de beperkte omvang van de filosofengemeenschap in die tijd, een generatie van kritische filosofen hebben voortgebracht, die zich in meerdere wetenschappelijke disciplines thuisvoelden en bovendien een kritische rol konden spelen in andere kennisdomeinen en onderzoeksvelden dan de filosofie zelf. En dat was precies wat ook de redactie van Krisis beoogde. Helaas werd diezelfde Centrale Interfaculteit in 1987 opgeheven en ingeruild voor de faculteit Wijsbegeerte, die aan de meeste Nederlandse universiteiten inmiddels een afdeling van de grotere faculteit Geesteswetenschappen is geworden. Filosofie is een wetenschappelijke discipline als alle andere geworden, 'centraal' en 'inter' zijn gesneuveld. ${ }^{1}$ Tegelijkertijd kon de redactie van Krisis er in de daaropvolgende jaren nieuwe voorvoegsels als 
'trans' of 'post' voor in de plaats stellen: zowel de samenstelling van de redactie als de inhoud van het tijdschrift waren meer en meer trans- of postdisciplinair geworden, met sociologen, politicologen en historici als redacteur, en science and technology-studies, genderstudies en cultural studies als nieuwe trans- of multidisciplines. Al met al leek de lange mars door de universitaire instituties toch enige resultaten op te leveren in de vorm van uiteenlopende theoretische kruisbestuivingen, die zowel neersloegen in de kolommen van Krisis als in nieuwe multidisciplinaire onderzoeksscholen en -instituten zoals het landelijke WTMC (vooral science and technology-studies ofwel STS) of het Amsterdamse ASCA (vooral cultural studies of cultural analysis) waar veel van het kritische filosofische onderzoek in de hoofdstad een nieuwe bedding vond. En er was meer! Tot zover het vrolijke verhaal van een lange mars van kritische intellectuele en filosofische praktijken waarin Krisis een rol van betekenis heeft gespeeld, en dat in de huidige digitale variant nog steeds speelt. Maar er is ook een ander verhaal.

\section{De hegemonie van homo economicus.}

De ondertitel van Ruud Abma's boek Een zaak van lange adem (2019) over de linkse uitgevers en boekhandelaren in Nijmegen verhult een zeker historisch ongemak: 'Hoe een Nijmeegs boekenimperium de studentenbeweging overleefde' legt alle nadruk op de uitzonderlijke kracht van een vorm van lokale samenwerking tussen gedreven uitgevers, studentenactivisten, onderzoekers en schrijvers, en kleine ondernemers (een drukker en een boekhandel) - een samenwerking die het product was van een radicale studentenbeweging maar tegelijk aan die beweging en haar historische lot ontsteeg. De linkse studentenbeweging, van de Kritische Universiteit tot de door communisten en radicale socialisten gedomineerde Landelijke Studenten Vakbond (LSVb) en de nog radicaler studentenbonden in Nijmegen en elders, verloor haar momentum rond 1980 en was een decennium later volkomen uitgedoofd. Abma laat zien hoe uitgever SUN, drukker SSP en boekhandel De Oude Mol zichzelf ondanks dat uitdovingsproces staande wisten te houden, ook al vereiste dat soms de nodige intellectuele dan wel praktische tournures. Wat de ondertitel echter verhult is dat het boekenimperium alleen kon overleven door geleidelijk aan van signatuur te veranderen. SUN verschoof de aandacht in haar fonds van (linkse) politiek en marxisme naar kunst, architectuur, geschiedschrijving, religie en mondjesmaat literatuur. De boekhandel werd overgenomen door een andere ondernemer en veranderde van naam en aanbod, en de drukker ging op in een groter bedrijf. Uiteindelijk was 
dat ook het lot van de uitgeverij, die in 2000 werd overgenomen door de wetenschappelijke uitgeverij Boom en in 2008 haar eigen naam verloor. Maar nog beslissender, vooral voor het kritische en alternatieve wetenschappelijke onderzoek, was de teloorgang van het complete pakket aan linkse wetenschappelijke tijdschriften dat door de SUN jarenlang met succes werd aangeboden. De meeste van die tijdschriften haalden het nieuwe millennium net of niet: Psychologie en Maatschappij werd in 2001 opgeheven, Te Elfder Ure, de ideologische vaandeldrager van de SUN, verdween al in 1988, Recht en Kritiek haalde 1996. Andere tijdschriften werden door meer 'algemene' uitgevers overgenomen, zoals Oase (architectuur) door NAiuitgevers en Tijdschrift voor Vrouwenstudies (sinds 1997 Genderstudies) door Amsterdam University Press. Wederom Ruud Abma, zelf in de jaren tachtig redacteur van Psychologie en Maatschappij, zoekt in een terugblik op het tijdschrift in de Academische Boekengids naar een verklaring voor die teloorgang en vindt die in wat hij de verstrakking van de academische cultuur in de loop van de jaren tachtig en negentig noemt: "Als gevolg daarvan zijn sociale wetenschappers tegenwoordig minder geneigd, of in de gelegenheid, tot lezen - en als ze dat al doen, kiezen ze voor tijdschriften die op hun specialisme betrekking hebben. Publiceren doen ze bij voorkeur, zij het meestal niet vrijwillig, in Engelstalige tijdschriften." (Abma 2010, 10) Abma wijst daarnaast op het beleid van de redactie als factor in de terugloop van de belangstelling: "Het beleid van de $P \& M$-redactie om zich te concentreren op culturele thema's, theoretische vraagstukken en een multidisciplinaire aanpak van psychologische onderwerpen was een natuurlijke, maar ook een riskante keuze. Zij was natuurlijk omdat de bezinning op de maatschappelijke rol en de inhoudelijke ontwikkeling van de psychologie vraagt om een benadering die zowel breed als diep is. Zij was riskant omdat $P \& M$ daarmee werd tot een tijdschrift voor intellectuelen, terwijl tegelijkertijd het academische klimaat - zeker binnen de psychologie - steeds minder intellectueel werd.” (Ibid.) Met de term 'intellectueel' slaat Ruud Abma vermoedelijk de spijker op zijn kop: de 'verstrakking' van het academische klimaat, waarop ik nog terugkom, betekende onder meer dat het wetenschappelijk onderwijs en onderzoek zich enerzijds steeds meer terugtrok achter strak afgebakende disciplinaire grenzen en anderzijds, onder andere middels nieuwe (soms interdisciplinaire) kundes en studies, een meer praktijkgerichte en beroepsgeoriënteerde invulling kreeg. Beide ontwikkelingen stonden haaks op de brede en diepgaande intellectuele pretenties van kritische tijdschriften als Psychologie en Maatschappij. Zeker was het ook zo dat de spankracht van de linkse studentenbeweging in 
de loop van twintig jaar was geminimaliseerd, maar daarop hadden de meeste kritische wetenschappelijke tijdschriften in de loop van de jaren tachtig wel degelijk een antwoord gevonden: allereerst door een meer autonome positie te kiezen tegenover 'de' beweging, en vervolgens door de eigen scope te verbreden: direct politieke onderwerpen maakten steeds vaker plaats voor een brede, culturele oriëntatie, voor kritisch grondslagenonderzoek en theoretische reflectie. Maar juist die brede, intellectuele invulling van het eigen wetenschapsgebied kreeg vervolgens te lijden onder dat verstrakte academische klimaat.

Die verstrakking verliep nogal ongemerkt: eind jaren zeventig werd het Maagdenhuis nog langdurig bezet uit protest tegen het voornemen studenten uit de besturen van vakgroepen te weren, maar sindsdien bleef het opvallend stil aan het universitaire front. In de jaren tachtig gingen universiteiten, mede onder druk van bezuinigingen, hun wetenschappelijke staf scherper evalueren en beoordelen, vooral waar het promoties en aantallen publicaties betrof, waarna in de jaren negentig een begin wordt gemaakt met wat je een bedrijfsmatige reorganisatie van de universiteit kunt noemen, een ontwikkeling die vrijwel overal ter wereld plaatsvindt. In Nederland trekt aanvankelijk vooral de Universiteit Twente de nodige aandacht door zichzelf uit te roepen tot ondernemende universiteit, maar in werkelijkheid gaat het hier om een algemeen patroon: het ideaal van een autonome wetenschappelijke gemeenschap wordt ingeruild voor een efficiënt en bedrijfsmatig werkend instituut voor wetenschappelijk onderwijs en onderzoek, dat "academici [wil] afleveren die verwervingsvaardigheden hebben, die flexibel en snel inzetbaar zijn waar behoefte is, die zich wèl voelen in een 'stormachtige' maatschappij", aldus het jaarverslag 1994 van de UT (Grit 2000, 102). Universiteiten versterken hun relaties met het bedrijfsleven, zetten meer in op toegepast onderzoek en contractonderzoek, investeren meer dan ooit in reclame- en marketingcampagnes, begeven zich op de mondiale 'studentenmarkt' en bouwen grootschalige, industriële science parks, waar de samenwerking met commerciële partijen fysiek gestalte krijgt. De homo economicus verovert stap voor stap het universitaire toneel en is halverwege het eerste decennium van de $21^{\text {ste }}$ eeuw dominant geworden in de academische cultuur. Output, impact en efficiency zijn de allesbepalende, Engelstalige motto's van het nieuwe universitaire managementjargon geworden, terwijl aloude waarden als Bildung, mondigheid, kritiek en intellectuele dan wel maatschappelijke relevantie nu gereserveerd worden voor de rituele mission statements bij de presentatie van de universitaire jaarcijfers $^{2}$. 


\section{Empirische filosofie?}

Intussen overleeft Krisis zelf ternauwernood de geleidelijke 'verstrakking' van het academische klimaat en de machtsgreep van de homo economicus ten koste van het intellectuele debat. Werd het blad bijna twee decennia in eigen beheer uitgegeven door een stichting, in 1997 adopteert Boom Uitgevers het tijdschrift om het na een gestage daling van het aantal abonnees te doen fuseren met het ook door Boom uitgegeven Kennis \& Methode, een aan Krisis verwant, van oorsprong wetenschapsfilosofisch tijdschrift dat allengs was geëvolueerd in de richting van wetenschapshistorisch en -sociologisch onderzoek en een podium bood voor de jonge traditie van science and technology-studies. Kennis \& Methode was er nog slechter aan toe dan Krisis, en leed waarschijnlijk aan dezelfde kwalen die een einde maakten aan Psychologie en Maatschappij: een wegzakkende belangstelling voor intellectuele breedte en diepgang bij haar abonnees en een verschuiving onder jonge onderzoekers richting Engelstalige publicaties onder druk van de verstrakking en de nieuwe output- of rendementscultuur. De fusie leverde Krisis een nieuwe ondertitel op: tijdschrift voor empirische filosofie, zoals $K \& M$ al werd aangeduid. Toch was die nieuwe ondertitel niet zozeer een concessie aan Kennis \& Methode (dat haar naam verloor), maar een uitgebreid inhoudelijk bediscussieerde, programmatische keuze, een keuze die grotendeels haaks stond op het beleid en de programma's van de faculteiten of afdelingen filosofie aan de Nederlandse universiteiten en eerder aansloot bij allerlei nieuwe, meer of minder interdisciplinaire studierichtingen en onderzoeksprogramma's zoals STS, cultural studies en onderzoeksscholen als WTMC of ASCA. Veel redacteuren, medewerkers en auteurs van Krisis waren niet langer of nooit verbonden (geweest) aan de filosofieopleidingen aan de Nederlandse universiteiten en dat ging meer en meer zijn stempel drukken op het blad zelf. Met de keuze voor 'empirische filosofie' werd daar in zekere zin recht aan gedaan, maar op een wel heel open en conflictueuze manier: in het allereerste nummer na de fusie tussen $K \& M$ en Krisis, bovendien nummer 1 van jaargang 1 van het nieuwe millennium, werd de empirische filosofie niet alleen programmatisch in de verf gezet, maar meteen ook al gerelativeerd en bekritiseerd: waar empirisch filosoof Annemarie Mol alle nadruk legt op de gesitueerdheid van alle kennis, daar kritiseert pragmatist René Gabriëls de doorgeslagen detranscendentalisering en cryptonormativiteit van veel empirisch filosofen. Beiden keren zich daarentegen eensgezind tegen wat Gabriëls de 'filosofologie' noemt: "Filosofologen zijn filosofen die vrijwel uitsluitend schrijven over wat hun collega's hebben geschreven." (Gabriëls 2000, 91) 
Empirisch filosofen en pragmatisten delen hun belangstelling voor alledaagse, politieke, ideologische, normatieve vraagstukken en de verschillende manieren waarop die worden geproblematiseerd, maar verschillen in de wijze waarop die problematiseringen vervolgens filosofisch verwerkt worden. Opvallender is echter dat beiden organisatorisch en inhoudelijk altijd een zekere afstand hielden (en houden) tegenover dat wat de meerderheid van de academische filosofen als hun kerntaken beschouwt. Empirisch of niet, het filosofische universum van Krisis leek steeds meer op dat van 'brede' theoretische tijdschriften als Theory, Culture \& Society, Configurations en Constellations, die alle drie een breed intellectueel palet hanteren, en bovendien gerelateerd zijn aan de traditie van de kritische theorie en open staan voor theorievorming en kritisch debat vanuit uiteenlopende filosofische stromingen. Dat laatste is uiteindelijk belangrijker dan het label 'empirisch', dat de reikwijdte van het tijdschrift al te zeer beperkte en bovendien de indruk wekte dat Krisis zich beperkte tot filosofische gevalsstudies of toegepaste filosofie, wat meer het domein van het tijdschrift Filosofie en Praktijk was. Na zes jaar werd de ondertitel wederom aangepast: het werd 'Tijdschrift voor actuele filosofie', wat in ieder geval duidelijk maakte dat het het blad niet om filosofologie ging, waarmee in wezen werd vastgehouden aan het oorspronkelijke redactionele programma uit 1980. Alleen was het inmiddels wel de vraag hoe het nu met die lange mars was gesteld. Welnu, die was eigenlijk al enige tijd stopgezet, of eigenlijk meer doodgelopen zonder dat iemand dat nog merkte.

\section{Krisis 2.0}

Om te overleven in het neoliberale academische klimaat van het Bologna-akkoord, de Dublindescriptoren, de citation indexes, de A-, B- en C-tijdschriften (Krisis was vanwege de Nederlandse taal per definitie een C-tijdschrift) en de publish-or-perish-cultuur op het gebied van wetenschappelijk onderzoek deed de redactie de nodige concessies: Krisis werd een peer reviewed tijdschrift, wat feitelijk de enige manier was om te overleven als een publicatieorgaan dat meetelde in de nieuwe academische pikorde en $d u s$ een relevant medium was voor kritische en linkse filosofen die een rol wensten te spelen in de wereld van de universitaire filosofie. Peer review was één ding, de taal nog zo'n 'dingetje': publiceren in het Nederlands ging langzaamaan gelijk staan aan academische zelfmoord. Het was leuk als je het erbij deed, maar het telde niet echt. Dat heette dan 'the vernacular' (het lokale of regionale of nationale): ook leuk! 
Maar geen punten. Kortweg: wat linkse of kritische sociaalwetenschappelijke tijdschriften als Psychologie en Maatschappij of Comenius in de jaren negentig overkwam, trof nu vrijwel de gehele Nederlandstalige markt van wetenschappelijke tijdschriften: geen (vooral beginnende) academicus wilde daar nog in publiceren. Tijdschriften fuseerden of verdwenen, of - en daar komt dat 'dingetje': kozen voor het Engels als voertaal. Hoe ging dat met Krisis? Na een kleine dertien jaar wilde de uitgever, Boom, niet meer verder - en Krisis was niet het enige tijdschrift dat daarvan het slachtoffer was. Was dit het einde? Bijna, waarschijnlijk. Maar Krisis was begonnen als een initiatief van studenten filosofie en had altijd vastgehouden aan de noodzaak van de input van de jongste generaties filosofen. De eerste jaren waren dat studenten, nu zijn het vooral promovendi, en geheel in tegenspraak met de academische cultuur van A-, B- en Cniveaus, publicatiescores e.d., bestaat ook nu de redactie voor een belangrijk deel uit promovendi of beginnend universitair docenten, die op grond van de geldende academische criteria natuurlijk geen enkel gezag zouden mogen hebben. In die zin heeft Krisis de lange mars volgehouden. Maar zonder uitgever ging het tijdschrift in zekere zin terug naar af: naar 'eigen beheer'. Maar betekende 'eigen beheer' in 1980 het zelf huren van een elektrische typemachine, het houden van een kleine ondersteuningsactie onder professoren en andere goed betaalde academici, het zelf drukken van de tijdschriften en het zelf verspreiden ervan over boekhandels in Nederland, in 2010, dertig jaar later, betekende eigen beheer vooral een eigen website met een digitaal archief. In 2007 houdt Boom ermee op en verschijnt het laatste papieren nummer van Krisis, vanaf 2008 gaat het tijdschrift als 'open access' filosofisch blad het net op. En wel tweetalig, althans als mogelijkheid: je kunt in Krisis in het Engels en het Nederlands publiceren, wat in de praktijk betekent dat er zo nu en dan een Nederlandstalig artikel verschijnt - en dat is gezien het de facto internationale karakter van het meeste wetenschappelijke, en daarmee ook filosofische, onderzoek inmiddels haast onvermijdelijk. Niettemin is de tweetaligheid niet onbelangrijk: het geeft aan dat het tijdschrift zich ondanks de academische hegemonie van het Engels wil blijven bemoeien met het filosofische en publieke debat in Nederland. Sowieso blijft de actualiteit het redactiebeleid sturen, getuige de recente thema's in Krisis: data-activisme, het antropoceen, drones, het klimaat, racisme, de toekomst van de universiteit (naar aanleiding van de Maagdenhuisbezetting in 2015), veiligheid en terrorisme, en als meest pregnante teken des tijds: populisme, neoconservatisme, nationalisme, ressentiment en burgerlijke ongehoorzaamheid. 
Het is duidelijk: al deze actuele vraagstukken en strijdperken hebben inmiddels mondiale reikwijdte gekregen, wat onderzoek en debat in het Engels onmisbaar maakt. Terwijl aan al deze vraagstukken en strijdperken filosofische dan wel intellectuele dimensies kleven - wat het voortbestaan van een filosofisch tijdschrift gericht op cruciale intellectuele discussies rechtvaardigt - is het niet uitgesloten dat de onlinevariant van Krisis een internationaler en mogelijk ook groter publiek trekt dan zijn papieren, Nederlandstalige voorloper. De meeste auteurs in het tijdschrift blijven echter toch Nederlandse filosofen en wetenschappers die zelf vaak met de Nederlandse (en Europese) varianten van al die mondiale intellectuele kwesties te maken krijgen. De neoliberale 'verbouwing' van de academische wereld, oftewel de zegetocht van wat sinds de laatste Maagdenhuisbezetting in 2015 het rendementsdenken is gaan heten, vindt overal ter wereld plaats, maar in de VS en Groot-Brittannië heeft dat her en der geleid tot de totale afbraak van de faculteiten Geesteswetenschappen, en daar is bijvoorbeeld in Duitsland, Frankrijk, België of Nederland geen sprake van. Nog niet? Of is er misschien heel geleidelijk sprake van een omslag? Enerzijds is het neoliberalisme na de grote crisis van 2008 alweer jarenlang business as usual, inclusief de cultuur van het New Public Management in de academische wereld, anderzijds is het leger van critici en afhakers groeiende. De intellectuele en politieke discussie over dit soort heikele kwesties moet, kortom, zowel op internationaal of mondiaal niveau als binnen een meer specifiek nationale context gevoerd worden. Een tijdschrift als Krisis kan nu een bescheiden rol spelen op beide niveaus, maar mist op dit moment wellicht voldoende nationale zichtbaarheid. Naast zijn online aanwezigheid zou een papieren 'jaarboek voor actuele filosofie' die zichtbaarheid kunnen vergroten, zeker nu het tijdschrift gevoed wordt door bijdragen van uiteenlopende sociale en geesteswetenschappers en het haar agenda minder dan ooit laat bepalen door de curricula en onderzoeksprogramma's van de $\mathrm{Ne}$ derlandse afdelingen en faculteiten Wijsbegeerte.

Natuurlijk is het niet alleen kommer en kwel in de Nederlandse academische filosofie, maar om nu te stellen dat het academische wijsgerige onderzoek een opvallende bijdrage levert aan het publieke en intellectuele debat in dit land, laat staan op internationaal niveau, lijkt me een schromelijke overdrijving. In die zin is de 'lange mars' van Krisis na veertig jaar geen groot succes geworden: de academische filosofie is weliswaar veranderd, maar niet in de richting die de redacteuren en medewerkers van Krisis wensten: van een grotere rol in het publieke debat of van een krachtiger kritisch-filosofische praktijk is na al die jaren geen sprake. Wel 
kun je stellen dat filosofen in het algemeen zichtbaarder zijn in de media, als essayist, columnist, programmamaker, onderzoeksjournalist of redacteur, maar dan gaat het doorgaans om filosofen die weinig affiniteit hebben met de academische onderzoeksagenda of daar hooguit een marginale rol in vervullen. Denk aan oprichter van De Correspondent Rob Wijnberg, Denker des Vaderlands Daan Roovers, NRC-ombudsman Sjoerd de Jong, Volkskrant-columnist Marjan Slob, essayisten als Coen Simons of Thijs Lijster, en vele anderen. In zekere zin is een tijdschrift als Krisis het beste op zijn plek in het grensgebied tussen de academie en de wereld van dit soort publieke intellectuelen, waarbij de 'academie' naar veel meer verwijst dan alleen naar de afdelingen of faculteiten wijsbegeerte. Dan kan het blad een intermediaire rol vervullen, als doorgeefluik tussen kritisch en vernieuwend filosofisch en wetenschappelijk onderzoek enerzijds en de filosofische antennes en breekijzers in het publieke debat anderzijds. Het doorgeefluik werkt daarbij in twee richtingen: niet langer laat het publieke debat zich eenzijdig sturen, inspireren en vernieuwen door de autoriteit van de wetenschapper, het publieke debat kan ook fungeren als inspiratiebron èn als bron van expertise en nieuwe kennis ten behoeve van de academische filosofie en het wetenschappelijk onderzoek. Geïnspireerd door en aansluitend bij het prachtige proefschrift van Joost Van Driessche, Muishond. Techno-wetenschappelijke, literaire en ethische bewegingen van taal (2017), heb ik een dergelijke intermediaire rol van de filosofie vergeleken met de praktijk van de etnograaf, niet uit een soort valse bescheidenheid of naïef empirisme, maar vanuit de voor de etnografie kenmerkende ironische betrokkenheid, een vorm van zelfvervreemding die zonder zelfvertrouwen èn zelfrelativering niet mogelijk is, en idealiter uitmondt in zelfvernieuwing - kortom het soort activiteit van tweede-orde die volgens René Gabriëls (2000) onmisbaar is voor de 'ware filosofie' - voor Krisis met andere woorden, of om af te sluiten met een citaat uit 'Muishond':

Niet alleen maakt de etnograaf de constructie van wetenschappen en technologieën van nabij mee, ze legt de techno-wetenschappelijke praktijk daarenboven naast verschillende andere praktijken, talen of, zoals Latour ze noemt, 'bestaanswijzen' - rechtspraak, religie, politiek, fictie enzovoort. Ze bezoekt zo te zeggen niet alleen Jan - die zich wetenschapper noemt en die vanuit wetenschappelijk oogpunt kijkt naar wat Piet zegt -; ze bezoekt niet alleen Piet - die zich fictieschrijver noemt en die vanuit retorisch oogpunt kijkt naar het werk van Jan -; ze bezoekt ook de vrouw van Jan - die zich juriste noemt en die zich bezighoudt met de auteursrechten van beiden -; ze bezoekt de 
broer van Piet - die zich politicus noemt en die zich laat inspireren door zowel de kennis van Jan als de verbeelding van Piet -; en ze bezoekt een gemeenschappelijke vriend - die econoom genoemd wil worden en die de waar van beiden prijst. (Van Driessche 2017, 17-18) $)^{3}$

Ziedaar het werkterrein van Krisis, 2.0 of niet. De lange mars werd een beetje een afscheid van de filosofie, maar dan toch als een poging haar in een nieuwe gedaante te doen herleven.

\section{Noten}

1 Dat de pretenties van de Centrale Interfaculteit er bij haar oprichting heel anders uitzagen dan hier wordt geschetst, en beter passen in het verzuilde politieke klimaat van de eerste decennia na WO II, laat Ido Weijers zien in een kritisch-historisch artikel in Krisis 58. In 1960 werd de Centrale Interfaculteit eigenlijk gebouwd als "een luchtkasteel (...), een knap maar zwevend bouwwerk." $(1995,84)$ 2 Zie Laermans (2016) voor een uitgebreide en kritische inventarisatie van het jargon van het neoliberale 'New Public Management'.

3 Van Driessche (2017, 17-18). Zie ook Boomkens (2016).

\section{Referenties}

Abma, Ruud. 2001. "Afscheid van Psychologie en Maatschappij." De Academische Boekengids 29 (oktober).

Abma, Ruud. 2019. Een zaak van lange adem. Hoe een Nijmeegs boekenimperium de studentenbeweging overleefde. Vantilt, Nijmegen.

Boomkens, René. 2016. "De blinde vlek van de filosofie: een leven leiden. Over nut en nadeel van de filosofie voor het leven." Algemeen Nederlands Tijdschrift voor Wijsbegeerte 108 (4): 485-508.

Gabriëls, René. 2000. "Simsalabimbambasaladusaladim. Over grote woorden." Krisis. Tijdschrift voor empirische filosofie 1 (1).

Grit, Kor. 2000. Economisering als probleem. Een studie naar de bedrijfsmatige stad en de ondernemende universiteit. Proefschrift Rijksuniversiteit Groningen.

Laermans, Rudi Lieven de Cauter \& Karel Vanhaesebrouck. 2016. Klein lexicon van het managementjargon. Een kritiek van de nieuwe newspeak. Berchem: EPO.

Van Driessche, Joost. 2017. Muishond. Techno-wetenschappelijke, literaire en ethische bewegingen van taal. Klement, Utrecht.

\section{Biografie}

René Boomkens is hoogleraar cultuurbeschouwing en cultuurgeschiedenis aan de Universiteit van Amsterdam en voorzitter van de vakgroep Cultuurwetenschappen. Van 1999 tot 2014 was hij hoogleraar sociale en cultuurfilosofie aan de Rijksuniversiteit Groningen en van 1998 tot 2003 bijzonder hoogleraar popmuziek aan de Universiteit van Amsterdam. Hij was medeoprichter en redacteur van Krisis, redacteur van De Gids en van de boekenreeks Kennis, Openbare Mening \& Politiek van uitgeverij Van Gennep. 